\title{
Application of BIM-technologies in tasks of quality management and labour safety
}

\author{
Vera Cherkina ${ }^{*}$, Natalia Shushunova and Julia Zubkova \\ Moscow State University of Civil Engineering, Yaroslavskoe shosse, 26, Moscow, 129337, Russia
}

\begin{abstract}
The use of information modeling technology, Building Information Modeling (BIM), for the quality control system and improving the safety level of buildings and structures allows for a much higher level of design, construction and operation. It is necessary to predict the different building conditions in the implementation of planning processes, that should be made safely and reasonably. This paper presents a summary of specific examples, that show the results of successful implementation of this method with reference to capital construction objects of varying complexity.
\end{abstract}

\section{Introduction}

This research is aimed at studying the BIM-technologies in tasks of quality management and labour safety in construction. Due to economic difficulties, construction companies and organizations have already think about the need to train specialists in the field with new requirements. By 2020 among construction specialties there will be a demand for such professors as a superintendent-watchers (a specialist who applies digital designs of facilities); manager-designer BIM, which uses new technologies information modeling, and eco-analytics in construction. In Russia, in 2016, the approved "Road map for the introduction of BIM in Russia" was already presented. Projects already prepared normative and technical documents and codes of practice in the field of BIM-designing. Mandatory requirements transition to BIM and the establishment of strict rules for the acceptance of documentation in the coordinating and approving state bodies will be introduced already in the next three to four years. The study examined the positive aspects of the mandatory transition to BIM for the entire construction industry application of modern technologies.

\section{Methodology}

In most developed European countries, the technologies in the BIM implementation for lean architectural practices have been successfully adopted $[1,2]$.

\footnotetext{
*Corresponding author: vera.cherkina@mail.ru
} 


\subsection{Introduction of BIM in Russia}

In Russia, the active growth of interest in information modeling technologies for buildings and structures, otherwise BIM-technologies, began about five years ago already then innovative companies began to use them. Over the past year, there has been a definite breakthrough in the introduction of appropriate modeling methods with the support of the state - the Ministry of Construction has presented a plan for a gradual transition to information modeling, and the Moscow State Expertise officially began to adopt BIM- models in addition to the standard set of documentation, thereby enabling the widespread introduction of new technologies in the construction sector. Building Information Modeling (BIM) is a process of collective creation and use of information about a building that forms the basis for all decisions throughout the life cycle of an object (planning, designing, issuing working documentation, construction, operation, demolition). BIM is based on a three-dimensional information model, on the basis of which the work of the investor, the customer, the general designer, the general contractor, the operating organization with the use of information processing technologies for quality management in construction [3,4]. The technologies of three-dimensional information modeling in themselves are not a novelty for the Russian construction industry. BIM- technologies have already been mastered and applied at the level of individual design and construction organizations.

For example, the company «SODIS» uses BIM-solutions Autodesk for the system of monitoring of structures, in particular, the Olympic facilities of Sochi. During the construction phase, sensors - accelerometers, inclinometers, geodetic sensors, controlling the absolute coordinates of the structures - were placed at the Olympic facilities. Subsequently, data from these devices began to flow into the information model and analyzed. During the earthquake in December 2012, the sensors installed in the Small Ice Arena recorded the event and analyzed its consequences. The monitoring system provided information that the parameters are normal and the building is safe. Application of information modeling technologies contributes to shortening the terms of the project, general improvement of the quality of the project documentation and the construction and installation works performed on its basis. For example, in the United States, savings due to the high quality of the project amounted to $10 \%$ of the contract value.

Quality control is an activity that involves carrying out measurements, examination, testing or evaluation of an object and comparing the results with the established requirements. The task of employees involved in quality control is to ensure that the products meet the requirements set by standards or other regulatory documents and are reliable, satisfactory and financially sustainable.

With regard to quality control of project documentation, the use of BIMtechnologies significantly reduces the number of requests for additional information and so-called collisions-errors at the design stage, practically eliminating inconsistencies between the object's constructions and its engineering networks. BIM modeling, for example, pushes back into the past such gross errors as the lack of technological holes for engineering systems, incorrect calculation of the volume of materials, the mass of structural elements. The number of errors caused by insufficiently efficiently organized teamwork between specialists engaged in the design of various sections is reduced by working in a unified information environment and using uniform regulations. It should be noted that the use of BIM-technologies along with undoubtedly positive influence on the general culture of the construction industry requires additional efforts, labor and financial resources from managers and specialists, especially in matters of information exchange. It is necessary to develop and understand the relevant normative and technical documents, and, above all, to 
formulate additional standards defining the terminology and requirements for information models, taking into account their correspondence to the stages of the life cycle of the planning, creation and operation of the facility. Unambiguous interpretation of terms is necessary for interaction between various project participants, regulatory and supervisory bodies. If the company does not have a quality control officer who owns BIM technology, problems with understanding standards, recommendations, instructions will inevitably arise. In this case, the quality may not increase, but seriously suffer. On the other hand, the participation of a quality specialist in BIM-modeling will ensure the high quality of the project documentation, accelerate the introduction of adjustments to the project and the formation of working documentation.

\subsection{BIM-modeling in the field of labor safety}

BIM-modeling in the field of labor safety allows to consider various combinations of problems leading to production risks. For example, in a construction project, a detailed study of the location of a tower crane will avoid the occurrence of an industrial risk. Dangerous zones and zones of workers' access to workplaces will be correctly and unmistakably designated.

At the company "Etalon ", using BIM-technology in the design and construction, identify three main tools for which the new approach directly affects: time control, quality control and labor protection control. The specialists, together with the OSH engineer, integrated the BIM model, government safety standards and risk assessment methodology into the system. As a result, at the residential complex under construction in the south of Moscow - Etalon City - the level of labor safety has become close to $90 \%$, which made this facility one of the safest in Russia. A virtual model in new modeling technologies will allow to identify and solve problems before they arise in reality, which will increase the operability of the participants in the construction process, including the stage of passing the examination.

As part of the implementation of the strategy of the Moscow Expertise on the use of building information modeling technologies, consideration of the first BIM project has been completed. In addition to the standard package of project documentation, a comprehensive information model of the capital construction project was provided for electronic expertise - a polyclinic for 550 places in the New Vatutinki microdistrict. The information model provided the opportunity to obtain additional projections and views not presented in the project documentation. The expert on labor protection and fire safety has checked and corrected two provisions: the maximum permissible distance from the most remote point of the room to the nearest evacuation exit; the maximum distance between the sensors of fire alarm.

The main burden of the introduction of these technologies into the practice of domestic companies should be borne by organizations participating in the project at a later stage, i.e. customers and general contractors, since they are the main beneficiaries of a better project - due to significant material savings, improving the quality of construction and installation works, and improving safety at the site. Due to the rapid development and adoption of BIM-related technologies, such as 4D CAD system, and others construction simulation methods, the use of these technologies for quality management and labour safety has become a growing research trend (Figure 1). 


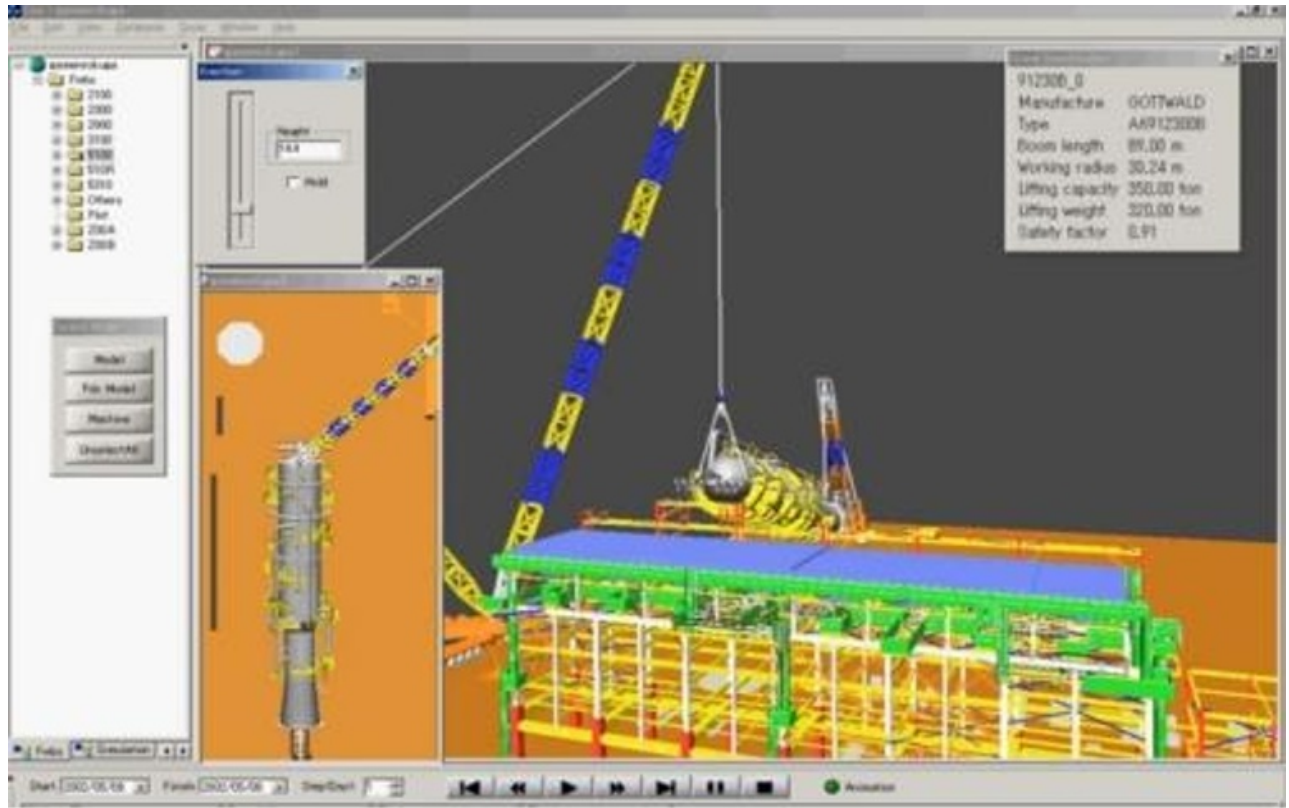

Fig. 1. 4D CAD system, built by combining the data of construction equipment.

BIM-based tools are used to be solved and performed further risk analysis in the AEC (Architecture, Engineering and Construction), such as application of BIM 5D Technology in Central Grand Project. [5, 6]. The challenges of implementing BIMTechnologies in the construction engineering industry in Finland was studied by professor Risto Tulenheimo [7].

\section{Results and discussion}

In our view, the most inclined to innovation are actively switching to the use of BIMtechnologies, and have already felt the benefits from their use.

It is interesting that in the tender documentation for the design of the hospital in Krasnoyarsk, the customer originally was tasked with developing a project in information modeling technology. It is possible that this project will enter the register of re-application projects, since, starting in 2016, the use of BIM-technology has become an obligatory

criterion for inclusion in this register according to the plan for the formation of a system of standard design in construction.

In Britain, the entire state order was transferred to BIM-technologies, and this allowed to reduce government spending by $30 \%$. In the United States, a special regulatory framework has been developed that supports the use of BIM. Actively promoting the implementation of information modeling Finland, Norway, Germany, France, South Korea, Singapore. Over a third of Western European BIM-technologies users (34\%) have over 5 years of experience using BIM (Figure 2). 


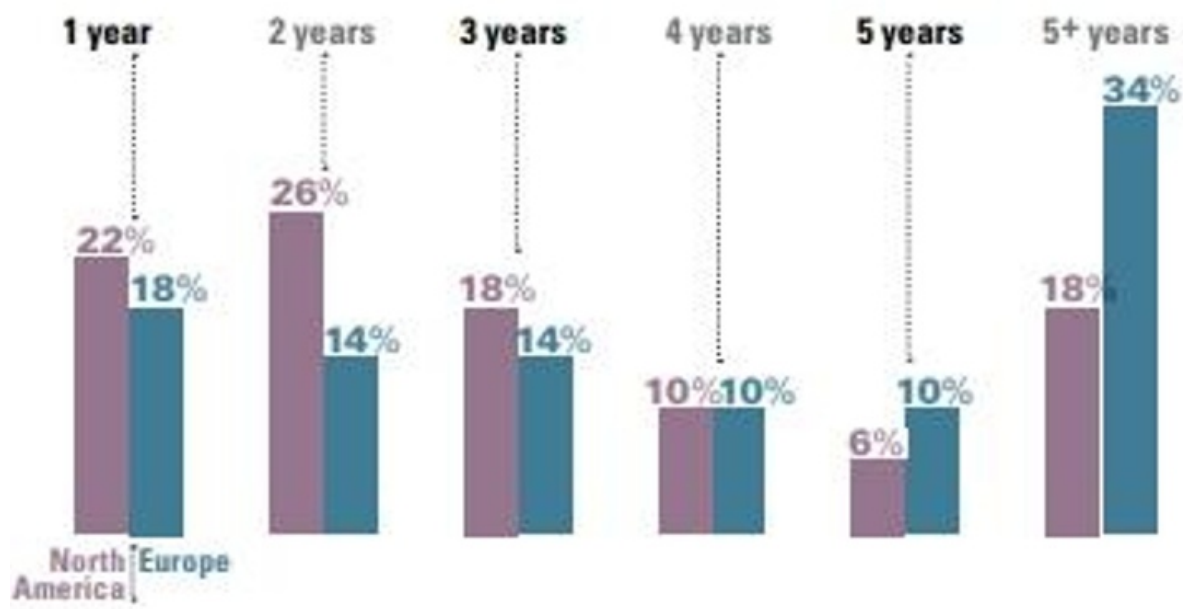

Fig. 2. The BIM-technologies users in Western European and North America.

In Russia, by 2019, the use of BIM-technology for projects that are financed from the state budget will become mandatory [8-10]. Most of the building community, which has not yet switched to BIM-technologies, has realized the necessity, and most importantly, the irreversibility of the changes taking place in the industry. The principles of modeling construction correspond to the methodological basis for the construction of smart cities [11- 13]. New buildings have to use the advanced technologies, based on the concept of innovation for sustainable development in the construction [14-16]. Therefore, in the near future, we should expect an avalanchelike increase in tasks, in solving which the information modeling method will provide a high level of quality management and labor safety.

\section{Conclusions}

With the aim of introducing BIM in Russia, the experience of advanced countries such as Norway, the Netherlands, Denmark, Germany has been studied BIM-Models. Since the 2016, in Great Britain the use of BIM-technologies is mandatory requirement for government contracts. In the United States, a special regulatory framework supporting the use of BIM. Managers and initiators of the large companies, such as McGraw-Hill Construction (MHC), part of The McGraw-Hill Companies, are being studied the normative base of the leading countries, and in Russia the way of transition to BIM is indicated: design with development of own norms and rules, most fully corresponding to the specifics of the legislative framework of the Russian Federation.

It must be noticed, that two of third of customers submitting for the examination BIM- model are private investors. Consequently, work in BIM at all stages, including expertise is recognized by the professional community as effective. In particular, it allows to increase the efficiency of work in the part expertise of project documentation and engineering results research. Working with BIM, an expert can more quickly find the necessary detail, to track the correspondence of constructive, architectural, volumeplanning, technological and other design solutions, norms of technical regulations. That is, in a global sense, it is more convenient and more effective and BIM is a modern trend, that positioned as the future of the construction industry. 


\section{References}

1. X. Wang, Perspectives in Science, 7 (2016)

2. Y. Arayici, P. Coates, L. Koskela, M. Kagioglou, K. O'Reilly, Automation in Construction, 20, 2 (2011)

3. N. D. Aziz, A. H. Nawawi, N. R. Ariff Procedia - Social and Behavioral Sciences, 234, 31 (2016)

4. Z. Hu, P. Tian, S. Li, J. Zhang, Advances in Engineering Software, 115 (2018)

5. Y. Zou, A. Kiviniemi, S. W. Jones, Safety Science, 97 (2017)

6. J. Xu, Procedia Engineering, 174 (2017)

7. R. Tulenheimo, Procedia Economics and Finance, 21 (2015)

8. N.P. Chetverik, Construction: New Technologies - New Equipment, 8 (2014)

9. S. Guo, T. Wei, Energy and Buildings, 127 (2016)

10. A. A. Volkov, L. V. Sukneva, Procedia Engineering, 91 (2014)

11. E. Korol, N. Shushunova, Procedia Engineering, 161, (2016)

12. O.A. Korol, Construction Materials, 6 (2015)

13. E. Korol, P. Kagan, T. Barabanova, I. Bunkina, International Journal of Applied Engineering Research, 11, 3 (2016)

14.V.G. Borkovskaya, E. Degaev, I. Burkova, MATEC Web of Conference 2018, Vol. 193 (2018)

15.V.G. Borkovskaya, Advanced Materials Research, Vol.860-863, Chapter 26 (2013)

16. V.G. Borkovskaya, D. Passmore, MATEC Web of Conference 2018, Vol. 193 (2018) 